\title{
Providing optimal regional care for ST-segment elevation myocardial infarction: a prospective cohort study of patients in the Hamilton Niagara Haldimand Brant Local Health Integration Network
}

\author{
Mathew Mercuri PhD, Michelle Welsford MD, Jon-David Schwalm MD, Shamir R. Mehta MD MSc, \\ Purnima Rao-Melacini MSc, Nicholas Valettas MD MASc, Tej Sheth MD, Michael Rokoss MD, \\ Sanjit S. Jolly MD MSc, James L. Velianou MD, Madhu K. Natarajan MD MSc
}

Abstract

Background: Although considered the evidence-based best therapy for ST-segment elevation myocardial infarction (STEMI), many patients do not receive primary percutaneous coronary intervention $(\mathrm{PCI})$ because of health care resource distribution and constraints. This study describes the clinical management and outcomes of all patients identified with STEMI within a region, including those who did not receive primary $\mathrm{PCI}$.

Methods: This study used a prospective cohort design. Patients presenting with STEMI to PCl- and non-PCl-capable hospitals in one integrated health region in Ontario were included in the study. The primary objective was to examine use of reperfusion strategies and timeliness of care. Secondary objectives included determining (through regression models) which variables were associated with mortality within 90 days, and describing patient uptake of risk-reducing therapies and activities post-STEMI.

Results: Between Apr. 1, 2010, and Mar. 31, 2013, data were collected on 2247 consecutive patients presenting with STEMI. Patients presenting to the $\mathrm{PCl}$-capable hospital were more likely to receive primary $\mathrm{PCl}(82.5 \% \mathrm{~V} .65 .2 \%, p<0.001)$ and be treated within optimal treatment times. However, there was no appreciable difference in mortality at 90 days post-STEMI between patients presenting to $\mathrm{PCl}$ - and non-PCl-capable hospitals $(7.8 \% \mathrm{v} .7 .5 \%, p=0.82)$, even after adjustment for acuity on presentation. Despite recognized risk factors, many patients were not taking evide- $\neq \neq$ nce-based medications for risk factor modification before STEMI.

Interpretation: A systematic approach to regional STEMI care focusing on timely access to the best available therapies, rather than the type of reperfusion provided alone, can yield favourable outcomes.

T-segment elevation myocardial infarction (STEMI) is a cause of significant morbidity and mortality. ${ }^{1}$ Whereas early myocardial reperfusion is crucial in treating STEMI, ${ }^{2}$ the clinical characteristics of patients and available resources both determine how this is best achieved. Choosing the best course of STEMI care requires the coordination of various services, including prehospital emergency medical services, emergency medicine and interventional cardiology. When it can be accomplished in a timely manner, reperfusion with primary percutaneous coronary intervention (PCI) is considered the evidence-based standard of care. ${ }^{3}$ However, primary PCI may not be feasible for all patients because of population-based geographic distribution of resources, patient comorbidity and resource constraints. ${ }^{4}$ Certain patients may benefit from timely fibrinolysis coupled with a pharmacoinvasive approach, 3,5 because fibrinolysis is available in all emergency departments (and some pre- hospital settings) and available to a broader population without the need for additional infrastructure. Thus, a regional STEMI program seeking to maximize patient and population outcomes requires a system approach devoted to ensuring that the best available treatment is provided given the context under which it is delivered.

Competing interests: Michelle Welsford has received a grant from the Ontario Academic Health Sciences Centres Alternate Funding Plan Innovation Fund. Sanjit Jolly has received a grant from Medtronic and speaker fees from AstraZeneca and St. Jude Medical. No competing interests were declared by the other authors.

This article has been peer reviewed.

Correspondence to: Madhu Natarajan, nataraja @mcmaster.ca CMAJ Open 2015.DOI:10.9778/cmajo.20140035 
Previous studies across Canada describe outcomes from regional primary PCI programs only. ${ }^{6-9}$ Few studies describe the management and outcomes of all STEMI patients within a region, including those who did not receive primary PCI. ${ }^{5,10}$ This paper will examine and describe the clinical management and outcomes of STEMI care for all patients, including those receiving primary PCI, fibrinolysis or no reperfusion therapy, presenting to hospitals within the Hamilton Niagara Haldimand Brant Local Health Integration Network in Ontario. Comparisons will be made between patients presenting to PCI- and non-PCI-capable centres. The intent is to identify care gaps and areas for improvement in the provision of STEMI care beyond the issues of improving timely primary $\mathrm{PCI}$ access.

\section{Methods}

\section{Setting}

The Hamilton Niagara Haldimand Brant Local Health Integration Network covers an area greater than $7000 \mathrm{~km}^{2}$, with a mixture of large urban areas and small rural communities and a population greater than 1.4 million. Health care is provided by 3 tertiary care hospitals, 9 community hospitals and 4 urgent care centres, served by 7 emergency medical services programs coordinated by 2 base hospitals and 4 dispatch centres. Primary PCI is available at a tertiary cardiac care centre located in a large urban community (Hamilton). ${ }^{11}$ In April 2010, a regional STEMI program was initiated to improve access, timeliness of care and overall outcomes for regional STEMI patients. A program-related reporting system facilitated implementation of the following strategies to improve STEMI care: 1) prehospital STEMI identification across the region, 2) paramedic redirection of STEMI patients to the primary-PCI-capable hospital, 3) a standardized reperfusion algorithm for emergency department staff (Appendix 1, available at www.cmajopen.ca/content/3/1/E1suppl/DC1), 4) standardized early discharge and repatriation with bridging clinic 5-7 days after discharge for all patients receiving care at the tertiary centre ${ }^{12}$ and 5) electronic 2-way audit and feedback system among STEMI care providers outlining quality indicators. The STEMI program included other evidence-based best practices, such as the single call activation system, rapid set up of the catheterization laboratory and oversight by a multidiscipline team..$^{13,14}$

\section{Study population and data collection}

Data were prospectively collected on a consecutive sample of STEMI patients presenting to PCI- and non-PCI-capable hospitals. Patients brought directly to the catheterization laboratory by emergency medical services were considered as presenting to the PCI centre. Patients were included if they had symptoms (chest pain or equivalent) for cardiac ischemia, with an electrocardiogram (ECG) demonstrating ST-segment elevation $\geq 0.1 \mathrm{mV}(1 \mathrm{~mm})$ in at least 2 contiguous precordial leads or 2 limb leads.

Patient information derived from a STEMI report form was entered into a registry by the program coordinator. Additional data regarding clinical characteristics, demographics and patient-specific health and system-related outcomes were collected from chart reviews. Health outcomes included death (in hospital and at 90 days post-STEMI), major bleeding, recurrent myocardial infarction (MI) and stroke. Management outcomes included reperfusion, hospital length of stay, time interval from hospital arrival to treatment (PCI, thrombolytic or fibrinolytic therapy) and proportion of patients receiving reperfusion within optimal treatment intervals (i.e., first hospital contact [arrival at emergency department] to primary PCI $<90 \mathrm{~min}$ for patients presenting to PCI site and $<120 \mathrm{~min}$ for patients transferred from another facility to PCI site or door to fibrinolysis $<30 \mathrm{~min}$ ). Time intervals were only calculated for 1) patients receiving either primary PCI or fibrinolysis, presenting within 12 hours of symptom onset and 2) when the first ECG was the diagnostic ECG, to reflect avoidable system delay and avoid contamination from patientrelated delays. Medications prescribed at discharge from hospital and adherence to the prescription regimen at 90 days after discharge were also considered; data for discharge medications were collected from chart review, and data for 90-day adherence were collected from standardized follow-up. A standardized follow-up telephone call was made 90 days postSTEMI to assess health outcomes (Appendix 2, available at www.cmajopen.ca/content/3/1/E1/suppl/DC1). Patients unavailable by telephone (following 3 attempts) were contacted by mail. Patients were considered lost to follow-up if they did not respond by phone or mail. A STEMI program coordinator reviewed all case report forms for completeness and accuracy and followed up with health care providers and medical records where applicable. A cardiologist independently confirmed all STEMI cases and outcomes. Ethics approval for the project was obtained from each participating hospital's institutional review board.

\section{Primary and secondary objectives}

The primary objective was to examine the use of reperfusion strategies and timeliness of care and compare them between patients presenting to PCI- and non-PCI-capable hospitals. The secondary objective was to determine which variables were associated with mortality within 90 days of STEMI. In addition, the study sought to describe patient uptake of riskreducing therapies and activities post-STEMI.

\section{Statistical analysis}

Dichotomous variables were compared using $\chi^{2}$ tests. Group medians and means were compared using the Wilcoxon rank sum test and Student $t$ test, respectively. Univariate logistic regression models were developed to determine which variables were associated with mortality within 90 days of initial STEMI. Variables considered for inclusion were age ( $\geq 75 \mathrm{yr})$, gender, history of diabetes, history of MI, history of anemia, Killip class 3-4, anterior MI, medications given before admission (any of acetylsalicylic acid, clopidogrel, statins, ace inhibitor, angiotensin II receptor blocker or $\beta$-blockers), left ventricular ejection fraction $\leq 35 \%$ during admission, reperfusion with primary PCI or fibrinolysis, symptom onset to emergency department arrival $>6$ hours, overall ST deviation $\geq 8 \mathrm{~mm}$ on diagnostic ECG, optimal time to treatment, estimated glomerular filtration rate, 
presentation hospital (PCI or non-PCI) and mode of presentation (emergency medical services or self-transport). Variables significant at $p<0.1$ in the univariate models were included in a multivariable logistic regression model. History of anemia and left ventricular ejection fraction $\leq 35 \%$ were significant; however, these variables were not included in the final model, because they were significantly correlated with estimated glomerular filtration rate and Killip class, respectively. Model fit was evaluated using a Hosmer-Lemeshow goodness-of-fit test and $\mathrm{C}$ statistics. The bootstrap resampling technique was used to determine the predictors of mortality. ${ }^{15}$ All analyses were performed using Statistical Analysis Systems version 9.2 for UNIX (SAS Institute).

\section{Results}

\section{Demographics and clinical characteristics}

Between Apr. 1, 2010, and Mar. 31 2013, 2247 STEMI patients were identified. Sixty-six patients were excluded from the analysis because either they died immediately after presentation to hospital before treatment $(n=12)$ or they were already admitted to hospital when the STEMI occurred $(n=54)$ (Figure 1). Follow-up data were available for 2043 patients at the time of discharge and 1839 patients at 90 days post-discharge. Approximately $84.8 \%$ of patients presented with a history of more than 1 cardiac risk factor. Patients presenting to PCI- and non-PCI-capable centres were reasonably similar (Table 1). Patients presenting to a PCI-capable

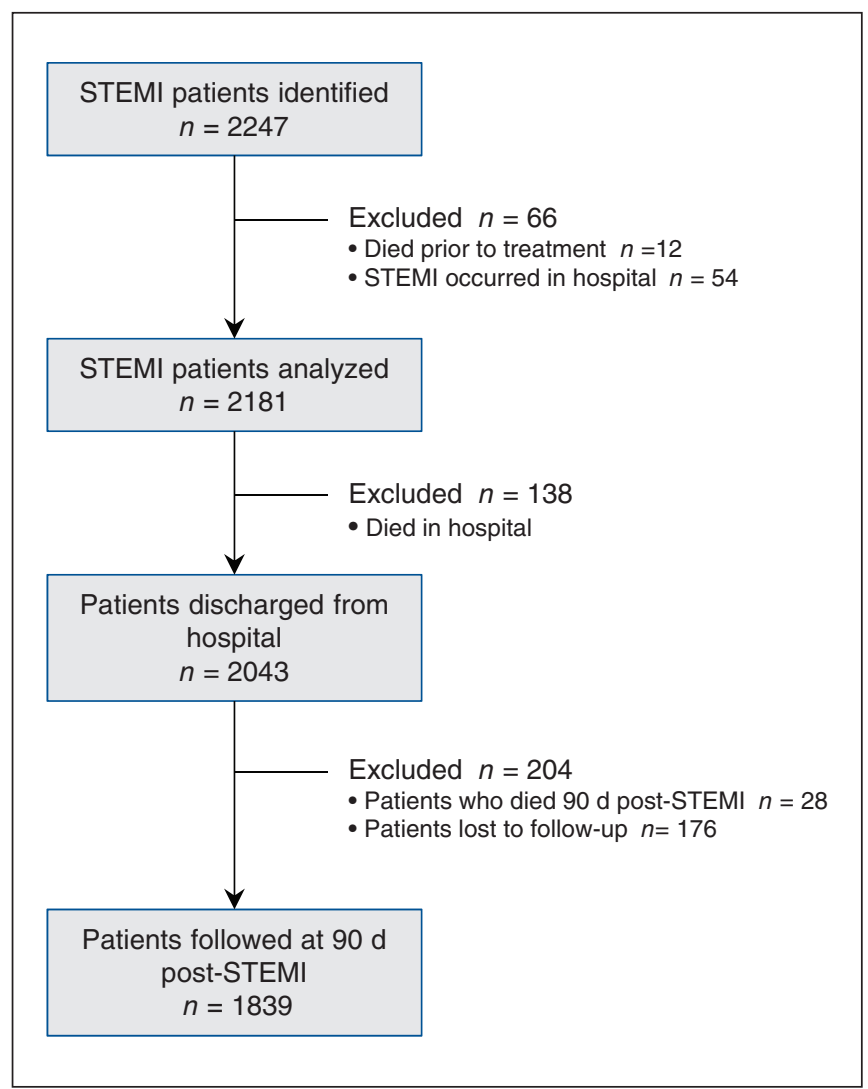

Figure 1: Patients involved in the study. centre were more likely to have a history of stroke or transient ischemic attack, diabetes or anemia, and to present via emergency medical services.

\begin{tabular}{|c|c|c|c|}
\hline \multirow[b]{2}{*}{ Characteristic } & $\begin{array}{l}\mathrm{PCl} \text {-capable } \\
\text { centre; no. (\%) } \\
\text { of patients }\end{array}$ & $\begin{array}{l}\text { Non-PCl- } \\
\text { capable centre; } \\
\text { no. }(\%) \text { of } \\
\text { patients }\end{array}$ & \multirow{2}{*}{$\begin{array}{c}p \text { value } \\
\left(\chi^{2}\right)\end{array}$} \\
\hline & $n=731^{*}$ & $n=1450^{*}$ & \\
\hline Age $>75 \mathrm{yr}$ & $138(18.9)$ & $269(18.6)$ & 0.85 \\
\hline Female & 207 (28.3) & $399(27.5)$ & 0.16 \\
\hline \multicolumn{4}{|l|}{ History of } \\
\hline $\begin{array}{l}\text { Coronary artery } \\
\text { disease }\end{array}$ & $154(21.1)$ & 268 (18.5) & 0.15 \\
\hline $\mathrm{PCl}$ & $81(11.1)$ & $138(9.5)$ & 0.25 \\
\hline CABG surgery & $29(4.0)$ & $37(2.6)$ & 0.07 \\
\hline MI & $124(17.0)$ & 216 (14.9) & 0.21 \\
\hline $\begin{array}{l}\text { Congestive } \\
\text { heart failure }\end{array}$ & $17(2.3)$ & $22(1.5)$ & 0.18 \\
\hline Stroke or TIA & $47(6.4)$ & $64(4.4)$ & 0.04 \\
\hline Diabetes & $176(24.1)$ & $282(19.4)$ & 0.01 \\
\hline Hypertension & 381 (52.1) & $749(51.7)$ & 0.84 \\
\hline Dyslipidemia & $271(37.1)$ & $573(39.6)$ & 0.26 \\
\hline Anemia & $120(16.4)$ & $170(11.7)$ & 0.002 \\
\hline Current smoker & $298(40.8)$ & $582(40.1)$ & 0.78 \\
\hline eGFR < 60† & $\begin{array}{c}168 \\
(24.0 ; n=699)\end{array}$ & $\begin{array}{c}315 \\
(22.5 ; n=1400)\end{array}$ & 0.43 \\
\hline Killip class 3 or 4 & $132(18.1)$ & $224(15.4)$ & 0.12 \\
\hline TIMI STEMI > 3† & $\begin{array}{c}342 \\
(49.4 ; n=692)\end{array}$ & $\begin{array}{c}650 \\
(47.0 ; n=1383)\end{array}$ & 0.30 \\
\hline Anterior MI & 280 (38.3) & $604(41.7)$ & 0.13 \\
\hline $\begin{array}{l}\text { ST-segment } \\
\text { deviation }>8 \mathrm{~mm}\end{array}$ & $485(66.3)$ & $929(64.1)$ & 0.29 \\
\hline $\begin{array}{l}\text { Intubation, } \\
\text { ventilation }\end{array}$ & $68(9.3)$ & $104(7.2)$ & 0.08 \\
\hline CPR, defibrillation & $60(8.2)$ & $147(10.1)$ & 0.15 \\
\hline Inotropes & $55(7.5)$ & $111(7.7)$ & 0.91 \\
\hline LVEF $\leq 35 \% \dagger$ & $\begin{array}{c}130 \\
(19.7 ; n=661)\end{array}$ & $\begin{array}{c}237 \\
(18.8 ; n=1261)\end{array}$ & 0.64 \\
\hline Presented via EMS & $598(81.8)$ & $713(49.2)$ & $<0.001$ \\
\hline $\begin{array}{l}\text { ECG in } \\
\text { ambulance }\end{array}$ & 138 (18.9) & $416(28.7)$ & $<0.001$ \\
\hline $\begin{array}{l}\text { Symptom onset } \\
<12 \mathrm{hr}\end{array}$ & $640(87.6)$ & $1239(85.4)$ & 0.18 \\
\hline \multicolumn{4}{|c|}{$\begin{array}{l}\text { Note: } C A B G=\text { coronary artery bypass graft, } C P R=\text { cardiopulmonary } \\
\text { resuscitation, ECG, electrocardiogram, eGFR = estimated glomerular filtration } \\
\text { rate, EMS = emergency medical services, LVEF = left ventricular ejection fraction, } \\
\text { MI = myocardial infarction, } P C I=\text { percutaneous coronary intervention, STEMI = } \\
\text { ST-segment elevation myocardial infarction, TIA = transient ischemic attack, } \\
\text { TIMI = thrombolysis in myocardial infarction. } \\
\text { *Unless otherwise indicated. } \\
\text { tNumber in parentheses is the number of patients with available values for that } \\
\text { variable. }\end{array}$} \\
\hline
\end{tabular}




\section{Management strategy}

Management and health outcomes are shown in Table 2. Most patients were treated with primary PCI, with a higher proportion in the PCI centre group $(82.5 \%$ v. $65.2 \%$, $p<0.001)$. Rate of fibrinolysis was higher in patients in the non-PCI-centre group (19.0\% v. $0.8 \%, p<0.001)$. Of the 282 patients who received fibrinolytic therapy, 190 (67.4\%) were referred for rescue PCI; of the remaining 92 patients, only 36 (39.1\%) were referred for pharmacoinvasive PCI within 24 hours of fibrinolysis (data not shown). Only 2 of the 7 emergency medical services programs servicing the region implemented the bypass strategy for direct transport to the PCI centre. Furthermore, of the 1311 patients who presented via emergency medical services, only 554 had ECG acquisition in the ambulance before arrival at hospital (Table 1).

\section{Outcomes}

A total of 138 (6.3\%) patients died before discharge from hospital; with an additional 28 confirmed deaths at 90 days postSTEMI (1.3\%). There were no observed differences in either mortality or other major cardiac events at both time points based on which hospital the patient presented to (i.e., PCI- v. non-PCI-capable centre). The time interval from arrival to primary PCI was significantly shorter for patients who presented to the PCI-capable centre compared to non-PCI-capable hospitals (73 $\mathrm{min}$ v. $113 \mathrm{~min}, p<0.001$ ). There were no appreciable

Table 2: Management and health outcomes by centre type

\begin{tabular}{|c|c|c|c|}
\hline \multirow[b]{2}{*}{ Outcome } & $\begin{array}{l}\mathrm{PCl}-\text { capable } \\
\text { centre; no. }(\%) \\
\text { of patients }\end{array}$ & $\begin{array}{l}\text { Non-PCl- } \\
\text { capable centre; } \\
\text { no. }(\%) \text { of } \\
\text { patients }\end{array}$ & \multirow{2}{*}{$\begin{array}{c}p \text { value } \\
\left(\chi^{2}\right)\end{array}$} \\
\hline & $n=731^{*}$ & $n=1450^{*}$ & \\
\hline Primary PCI & 603 (82.5) & 946 (65.2) & $<0.001$ \\
\hline Catheterization only & 84 (11.5) & $121(8.3)$ & 0.02 \\
\hline Fibrinolytic therapy & $6(0.8)$ & $276(19.0)$ & $<0.001$ \\
\hline Rescue PCI & $5(0.7)$ & $185(12.8)$ & $<0.001$ \\
\hline $\begin{array}{l}\text { Pharmacoinvasive } \\
\mathrm{PCl}\end{array}$ & $1(0.01)$ & $35(2.4)$ & $<0.001$ \\
\hline No reperfusion & 38 (5.2) & $107(7.4)$ & 0.05 \\
\hline Death in hospital & $48(6.6)$ & $90(6.2)$ & 0.7 \\
\hline Death (90 d) & $57(7.8)$ & $109(7.5)$ & 0.8 \\
\hline Repeat MI & $7(1.0)$ & $21(1.4)$ & 0.3 \\
\hline Stroke & $5(0.7)$ & $8(0.6)$ & 0.7 \\
\hline CABG & $38(5.2)$ & $74(5.1)$ & 0.9 \\
\hline $\begin{array}{l}\text { Major bleed } \\
\text { (without CABG) }\end{array}$ & $15(2.1)$ & $19(1.3)$ & 0.2 \\
\hline Length of stay $\leq 3 \mathrm{~d} \dagger$ & $\begin{array}{c}317 \\
(46.8 ; n=677)\end{array}$ & $\begin{array}{c}455 \\
(33.5 ; n=1360)\end{array}$ & $<0.001$ \\
\hline \multicolumn{4}{|c|}{$\begin{array}{l}\text { Note: } \mathrm{CABG}=\text { coronary artery bypass graft, } \mathrm{MI}=\text { myocardial infarction, } \mathrm{PCl}= \\
\text { percutaneous coronary intervention. } \\
\text { *Unless otherwise indicated. } \\
\text { tNumber in parentheses is the number of patients with available values for that } \\
\text { variable. }\end{array}$} \\
\hline
\end{tabular}

differences between groups regarding the other performance variables (Table 3). The proportion of patients treated within optimal treatment intervals at PCI- and non-PCI-capable hospitals were $70.8 \%$ and $58.7 \%$, respectively (Table 3 ).

The multivariable regression model showed that presenting to a PCI-capable centre was not a significant predictor of mortality even after adjustment for patient acuity, comorbidities, mode of transportation and timeliness of care (Table 4). The bootstrap analysis indicated that optimal time to treatment, symptom onset to emergency department arrival $>6$ hours and a history of diabetes were significant in $<50 \%$ of the simulation samples. However, we believe these variables were clinically important and thus retained them in the final model.

\section{Risk factor modification post-STEMI}

Attendance at risk factor modification programs after discharge from hospital was suboptimal. Only $35.7 \%$ of all patients either attended or had a scheduled appointment for cardiac rehabilitation at 90 days, and only $4.2 \%$ of patients attended a smoking cessation program (data not shown). However, there was a significant drop in the proportion of patients reporting as "currently a smoker" (40\% at time of STEMI and $15 \%$ at 90 days post-STEMI, $p<0.001$ ) (data not shown).

Although most patients presented with at least 1 risk factor for coronary disease, the baseline use of medications for prevention of MI or risk factor modification before presentation was low (Table 5). Use of medications prescribed at discharge was good with some attrition at 90 days (Table 5).

\section{Interpretation}

\section{Main findings}

In this large regional program, there were variations in reperfusion management of STEMI patients that reflected local

\begin{tabular}{|c|c|c|c|}
\hline & $\begin{array}{l}\mathrm{PCl} \text {-capable } \\
\text { centre; median } \\
\text { time (IQR), } \text { min }^{*}\end{array}$ & $\begin{array}{c}\text { NonPCl- } \\
\text { capable centre; } \\
\text { median time } \\
\text { (IQR), min* }\end{array}$ & \\
\hline Interval & $n=501$ & $n=960$ & value† \\
\hline $\begin{array}{l}\text { Symptom onset to } \\
\text { first arrival at ED }\end{array}$ & $86(57-144)$ & $80(48-160)$ & 0.2 \\
\hline Arrival to first ECG & $8(5-14)$ & $8(3-18)$ & 0.6 \\
\hline Arrival to primary $\mathrm{PCl}$ & $73(53-93)$ & $113(96-142)$ & $<0.01$ \\
\hline $\begin{array}{l}\text { Arrival to thrombolytic } \\
\text { or fibrinolytic therapy }\end{array}$ & $22.5(16-32)$ & $32(17-57)$ & 0.3 \\
\hline $\begin{array}{l}\text { Reperfusion within } \\
\text { optimal treatment } \\
\text { intervals, } n(\%)\end{array}$ & $353(70.8)$ & $564(58.7)$ & $<0.001$ \\
\hline
\end{tabular}

Note: $E C G$ = electrocardiogram, ED = emergency department, IQR = interquartile range. Time intervals were calculated for 1) patients receiving either primary $\mathrm{PCl}$ or fibrinolysis, 2) presenting within $12 \mathrm{hr}$ of symptom onset and 3) where the first ECG was the diagnostic ECG.

*Unless otherwise indicated.

†Two-sample Wilcoxon test. 
capabilities. However, median time to reperfusion met evidence-based benchmarks (described in the Methods section), and there was no difference in 90-day mortality rates between patients presenting to PCI- and non-PCI-capable centres. Once the patient entered the STEMI program, the system identified the best management strategy to improve outcome within the patient's clinical and geographic context. However, numerous patients presented to non-PCI-capable hospitals, especially in rural areas, making it less likely they would be able to access primary PCI within the recommended benchmarks.

\section{Explanation and comparison with other studies}

Research and organization of care for STEMI has focused on both ensuring timely access and increasing the proportion of patients receiving primary PCI over fibrinolysis. ${ }^{10,13,14,16-19}$ Our data suggest that even where best practices for regional STEMI care are implemented, some patients may still require fibrinolysis. The presented regression model is consistent with the accepted paradigm that time to reperfusion is an important predictor of STEMI outcomes. ${ }^{3}$ However, our data suggest that other clinical and process variables are important. We also observed that the proportion of patients not receiving reperfusion therapy was less than $10 \%$, consistent with recent reports from Europe showing that the rate of nonreperfusion is much less than the commonly accepted rate of $30 \%$ in well-established systems of STEMI care. ${ }^{20,21}$

Several issues relating to further improvements in coordination of care and prevention were identified as potentially impacting care and outcomes: 1) a minority of patients eligible for diagnostic catheterization within 24 hours of fibrinolytic therapy actually received it. There is accumulating evidence that where primary PCI is not possible, reasonable outcomes could be achieved with fibrinolysis administration combined

\begin{tabular}{|llc|}
\hline \multicolumn{2}{|l|}{ Table 4: Risk factors for mortality } & \\
\hline Variable & OR $(95 \% \mathrm{Cl})$ & $p$ value \\
\hline Killip class 3 or 4 (yes v. no) & $5.07(3.45-7.44)$ & $<0.0001$ \\
\hline eGFR $\leq 60$ (yes v. no) & $3.14(2.14-4.61)$ & $<0.0001$ \\
\hline Age $\geq 75$ yr & $2.21(1.49-3.27)$ & $<0.0001$ \\
\hline Transportation (EMS v. self) & $2.01(1.27-3.19)$ & 0.003 \\
\hline Reperfusion (yes v. no) & $0.58(0.39-0.85)$ & 0.005 \\
\hline History of diabetes (yes v. no) & $1.63(1.09-2.43)$ & 0.02 \\
\hline $\begin{array}{l}\text { Optimal time to treatment } \\
\text { (yes v. no) }\end{array}$ & $0.54(0.34-0.87)$ & 0.01 \\
\hline $\begin{array}{l}\text { Symptom onset to ED arrival } \\
>6 \text { hr (yes v. no) }\end{array}$ & $1.47(0.98-2.20)$ & 0.07 \\
\hline $\begin{array}{l}\text { PCl-capable centre } \\
\text { presentation (yes v. no) }\end{array}$ & $0.89(0.60-1.33)$ & 0.6 \\
\hline
\end{tabular}

Note: $\mathrm{Cl}=$ confidence interval, $\mathrm{ED}=$ emergency department, eGFR = estimated glomerular filtration rate, EMS = emergency medical services, $\mathrm{PCl}=$ percutaneous coronary intervention, $\mathrm{OR}=$ odds ratio. All variables included in the final model are presented. Eighty-two patients were not included in the model because some variables had missing values for these patients. The HosmerLemeshow goodness-of-fit test showed good model fit $(p=0.572)$, C statistic = 0.85 . with an early pharmacoinvasive approach; ${ }^{22-25}$ 2) implementation of an emergency medical services bypass strategy was only achieved in a minority of EMS programs servicing the region; 3) fewer patients were discharged within 3 days post- STEMI in the non-PCI-capable hospitals compared with the PCIcapable hospital; 4) participation in cardiac rehabilitation and risk modification programs was suboptimal despite a formalized discharge practice and availability of a bridging clinic and phone call at 7 days after discharge from hospital for all patients at the PCI centre; 5) despite the high rate of cardiac risk factors upon presentation (specifically $>50 \%$ and $>30 \%$ of patients self-reported hypertension and dyslipidemia, respectively), many patients were not taking medications for prevention of coronary artery disease. ${ }^{26,27}$ Although we could not determine the influence of resource limitations or other access barriers on patient outcomes, this study highlights the need for a better understanding of patient behaviour and raises the possibility that targeted education and improved resource allocation for rehabilitation and smoking cessation programs, and medication access and regimen adherence may maximize benefits. ${ }^{28}$

A significant proportion of patients did not access care via emergency medical services, including $>50 \%$ of those presenting to non-PCI-capable hospitals. The large discrepancy in the use of emergency medical services between PCI- and non-PCI-capable hospitals can, in part, be explained by the direct transfer strategy of the STEMI program, where patients with a diagnosis in the field could bypass the closest emergency department in favour of the PCI-capable centre. The overall rate of patients with STEMI presenting via emergency medical services was consistent with previous studies. ${ }^{29-32}$ Although many patients may be able to present to hospital faster via self-transport, using EMS may provide

\begin{tabular}{|c|c|c|c|}
\hline & $\begin{array}{l}\text { Prior to } \\
\text { presentation; } \\
\text { no. (\%) of } \\
\text { patients }\end{array}$ & $\begin{array}{l}\text { At time of } \\
\text { discharge;* } \\
\text { no. }(\%) \text { of } \\
\text { patients }\end{array}$ & $\begin{array}{c}\text { At } 90 \text { d post-Ml; } † \\
\text { no. }(\%) \text { of } \\
\text { patients }\end{array}$ \\
\hline Medication & $n=2181$ & $n=2043$ & $n=1839$ \\
\hline $\begin{array}{l}\text { ACE + ARB } \\
\text { inhibitor }\end{array}$ & $636(29.2)$ & 1740 (85.2) & $1431(77.8)$ \\
\hline Statin & $552(25.3)$ & 1878 (91.9) & 1585 (86.2) \\
\hline ASA & $445(20.4)$ & 1957 (95.8) & 1622 (88.2) \\
\hline ACE inhibitor & 435 (19.9) & $1622(79.4)$ & $1308(71.1)$ \\
\hline$\beta$-Blocker & 343 (15.7) & $1743(85.3)$ & 1396 (75.9) \\
\hline ARB inhibitor & 215 (9.9) & $125(6.1)$ & $143(7.8)$ \\
\hline Clopidogrel & $106(4.9)$ & $1688(82.6)$ & 1415 (76.9) \\
\hline Warfarin & $43(2.0)$ & 133 (6.5) & $94(5.1)$ \\
\hline
\end{tabular}


quicker and safer access to STEMI reperfusion. ${ }^{33}$ Improving the appropriate uptake of emergency medical services may improve timeliness of care and increase the proportion of patients eligible for primary PCI (via triage directly to the PCI-capable centre), therefore, improving outcomes in a segment of the regional STEMI population.

\section{Limitations}

Follow-up at 90 days after initial STEMI was incomplete. However, although those patients lost to follow-up were, on average, younger, there were no other appreciable differences in known characteristics (sex, Killip class and history of diabetes) between patients who were followed up and those who were lost to follow-up, as well as between PCI- and non-PCIcapable hospitals. No data were collected on patients who suffered STEMI but died before presenting to hospital. Thus, we were unable to determine the magnitude of unmet care. Understanding why these patients died before accessing care may reveal gaps in the provision of STEMI services. Finally, although $6.3 \%$ of patients were discharged with a prescription for an emerging antiplatelet therapy (i.e., prasugrel or ticagrelor), these medications were not included in the 90-day followup questionnaire.

\section{Conclusions and implications for practice and future research}

This study examined service provision and outcomes for all patients receiving STEMI care in a large geographic region. Identified gaps in the uptake of risk-modifying behaviours pre- and post-STEMI and management in hospital, such as use of cardiac catheterization after fibrinolysis treatment and standardized discharge, reveal opportunitites to improve patient outcomes in other ways beyond ensuring timeliness of care alone. Ongoing system measures aimed at minimizing these gaps and ensuring best available treatments given the context under which the patient presents may result in even better health outcomes to patients suffering STEMI.

\section{References}

1. Thom T, Haase N, Rosamond W, et al. Heart disease and stroke statistics 2006 Update: a report from the American Heart Association Statistics Committee and Stroke Statistics Subcommittee. Circulation 2006;113:e85-151.

2. Simes RJ, Topol EJ, Holmes DR Jr, et al. Link between the angiographic substudy and mortality outcomes in a large randomized trial of myocardial reperfusion: importance of early and complete infarct artery reperfusion. Circulation 1995;91:1923-8.

3. O'Gara PT, Kushner FG, Ascheim DD, et al. 2013 ACCF/AHA guideline for the management of ST-elevation myocardial infarction: a report of the American College of Cardiology Foundation/American Heart Association Task Force on Practice Guidelines. 7 Am Coll Cardiol 2013;61:e78-140.

4. Patel AB, Tu JV, Waters NM, et al. Access to primary percutaneous coronary intervention for ST-segment elevation myocardial infarction in Canada: a geographic analysis. Open Med 2010;4:e13-21.

5. Shavadia J, Ibrahim Q, Sookram S, et al. Bridging the gap for nonmetropolitan STEMI patients through implementation of a pharmacoinvasive reperfusion strategy. Can f Cardiol 2013;29:951-9.

6. Le May MR, So DY, Dionne R, et al. A citywide protocol for primary PCI in ST-segment elevation myocardial infarction. N Engl 7 Med 2008;358:231-40.

7. Le May MR, Wells GA, So DY, et al. Reduction in mortality as a result of direct transport from the field to a receiving center for primary percutaneous coronary intervention. 7 Am Coll Cardiol 2012;60:1223-30.

8. de Villiers JS, Anderson T, McMeekin JD, et al; Foothills Interventional Cardiology Service; Calgary STEMI QIHI Group. Expedited transfer for primary percutaneous coronary intervention: a program evaluation. CMAF 2007; 176:1833-8.
9. Chan AW, Kornder J, Elliot H, et al. Improved survival associated with prehospital triage strategy in a large regional ST-segment elevation myocardial infarction program. FACC Cardiovasc Interv 2012;5:1239-46.

10. Jollis JG, Roettig ML, Aluko AO, et al. Implementation of a statewide system for coronary reperfusion for ST-segment elevation myocardial infarction. 7AMA 2007;298:2371-80.

11. Mercuri M, Natarajan MK, Holder DH, et al. Insight into capacity planning for cardiac catheterization services: policy lessons learned from "Looking in the Mirror" over a decade. Health Policy 2009;91:314-20.

12. Kotowycz MA, Cosman TL, Tartaglia C, et al. Safety and feasibility of early hospital discharge in ST-segment elevation myocardial infarction - A prospective and randomized trial in low-risk primary percutaneous coronary intervention patients (the Safe-Depart Trial). Am Heart 7 2010;159:117.e1-6.

13. Bradley EH, Nallamothu BK, Curtis JP, et al. Summary of evidence regarding hospital strategies to reduce door-to-balloon times for patients with ST-segment elevation myocardial infarction undergoing primary percutaneous coronary intervention. Crit Patbw Cardiol 2007;6:91-7.

14. Bradley EH, Curry LA, Webster TR, et al. Achieving rapid door-to-balloon times: how top hospital improve complex clinical systems. Circulation 2006; 113:1079-85.

15. Austin PC, Tu JV. Bootstrap methods for developing predictive models. Am Stat 2004:58:131-7.

16. Diercks DB, Kontos MC, Chen AY, et al. Utilization and impact of pre-hospital electrocardiograms for patients with acute ST-segment elevation myocardial infarction: data from the NCDR (National Cardiovascular Data Registry) ACTION (Acute Coronary Treatment and Intervention Outcomes Network) Registry. 7 Am Coll Cardiol 2009;53:161-6.

17. Ting HH, Rihal CS, Gersh BJ, et al. Regional systems of care to optimize timeliness of reperfusion therapy for ST-elevation myocardial infarction: the Mayo Clinic STEMI Protocol. Circulation 2007;116:729-36.

18. McDermott KA, Helfrich CD, Sales AE, et al. A review of interventions and system changes to improve time to reperfusion for ST-segment elevation myocardial infarction. 7 Gen Intern Med 2008;23:1246-56.

19. Andersen HR, Nielsen TT, Rasmussen K, et al. A comparison of coronary angioplasty with fibrinolytic therapy in acute myocardial infarction. $N$ Engl $f$ Med 2003;349:733-42

20. Knot J, Widimsky $\mathrm{P}$, Wijns $W$, et al. How to set up an effective national primary angioplasty network: lessons learned from five European countries. EuroIntervention 2009;5:299, 301-9.

21. Huber K, Goldstein P, Danchin N, et al. Enhancing the efficacy of delivering reperfusion therapy: a European and North American experience with STsegment elevation myocardial infarction networks. Am Heart 7 2013;165: 123-32.

22. Armstrong PW, Gershlick A, Goldstein P, et al. The Strategic Reperfusion Early After Myocardial Infarction (STREAM) study. Am Heart 7 2010;160:30-35.e1.

23. Armstrong PW, Gershlick AH, Goldstein P. Fibrinolysis or primary PCI in ST-segment elevation myocardial infarction. N Engl 7 Med 2013;368:1379-87.

24. Cantor WJ, Fitchett D, Borgundvaag B, et al. Routine early angioplasty after fibrinolysis for acute myocardial infarction. N Engl 7 Med 2009;360:2705-18.

25. Le May MR, Wells GA, Labinaz M, et al. Combined angioplasty and pharmacological intervention versus thrombolysis alone in acute myocardial infarction (CAPITAL AMI study). 7 Am Coll Cardiol 2005;46:417-24.

26. Chow CK, Teo KK, Rangarajan S, et al. Prevalence, awareness, treatment, and control of hypertension in rural and urban communities in high-, middle-, and low-income countries. 7AMA 2013;310:959-68.

27. Anderson TJ, Gregoire J, Hegels RA, et al. 2012 update of the Canadian Cardiovascular Society guidelines for the diagnosis and treatment of dyslipidemia for the prevention of cardiovascular disease in the adult. Can 7 Cardiol 2013; 29:151-67.

28. Ivers NM, Schwalm JD, Grimshaw JM, et al. Delayed educational reminders for long-term medication adherence in ST-elevation myocardial infarction (DERLA-STEMI): protocol for a pragmatic, cluster randomized controlled Trial. Implement Sci 2012;7:54.

29. Mercuri M, Velianou JL, Welsford M, et al. Improving the timeliness of care for patients with acute ST-elevation myocardial infarction: implications of "self-transport" versus use of EMS. Healthc Q 2010;13:105-9.

30. So DY, Ha AC, Turek MA, et al. Comparison of mortality patterns in patients with ST-elevation myocardial infarction arriving by emergency medical services versus self-transport (from the prospective Ottawa Hospital STEMI Registry). Am 7 Cardiol 2006;97:458-61.

31. Luepker RV, Raczynski JM, Osganian S, et al. Effect of a community intervention on patient delay and emergency medical service use in acute coronary heart disease: the Rapid Early Action for Coronary Treatment (REACT) Trial. 7AMA 2000;284:60-7.

32. Mathews R, Peterson ED, Li S, et al. Use of emergency medical service transport among patient with ST-segment-elevation myocardial infarction: findings from the National Cardiovascular Data Registry Acute Coronary Treatment Intervention Outcomes Network Registry - Get With The Guidelines. Circulation 2011;124:154-63.

33. Song L, Yan $\mathrm{H}, \mathrm{Hu} \mathrm{D}$. Patients with acute myocardial infarction using ambulance or private transport to reach definitive care: Which mode is quicker? Intern Med f 2010;40:112-6. 
Affiliations: Department of Medicine (Mercuri), Division of Cardiology, Columbia University, New York; Department of Medicine (Mercuri, Schwalm, Mehta, Valettas, Sheth, Rokoss, Jolly, Velianou, Natarajan) Division of Cardiology, McMaster University, Hamilton, Ont.; Department of Medicine (Welsford), Division of Emergency Medicine, McMaster University, Hamilton, Ont.; Hamilton Health Sciences (Welsford, Schwalm, Mehta, Valettas, Sheth, Rokoss, Jolly, Velianou, Natarajan), Hamilton, Ont.; Population Health Research Institute (Schwalm, Mehta, Rao-Melacini, Sheth, Jolly, Natarajan), Hamilton, Ont.

Contributors: Mathew Mercuri, Madhu Natarajan, Michelle Welsford and Jon-David Schwalm were responsible for the conception and design of the study and acquisition of the data. Mathew Mercuri, Madhu Natarajan and Purnima Rao-Melacini drafted the manuscript. Purnima Rao-Melacini performed the statistical analysis. All of the authors contributed to the interpretation of the data, revised the manuscript for important intellectual content and approved the final version submitted for publication.

Disclaimer: The funding sources had no role in the study design, data collection or analysis, or writing of the manuscript.

Funding: This project was supported by a peer-reviewed grant from the Hamilton Academic Health Sciences Organization (2009-2012).

Supplemental information: For reviewer comments and the original submission of this manuscript, please see www.cmajopen.ca/content/3/1 /E1/suppl/DC1 